\title{
Why are sec-Alkylperoxyl Bimolecular Self-Reactions Orders of Magnitude Faster than the Analogous Reactions of tert-Alkylperoxyls? The Unanticipated Role of $\mathbf{C H}$ Hydrogen Bond Donation.
}

\begin{abstract}
Richmond Lee, ${ }^{a}$ Ganna Gryn'ova, ${ }^{a},+$ K. U. Ingold ${ }^{*}, \mathrm{~b}$ and Michelle L. Coote*,a
High-level ab initio calculations are used to identify the mechanism of secondary (and primary) alkylperoxyl radical termination and explain why their reactions are much faster than their tertiary counterparts. Contrary to existing literature, the decomposition of both tertiary and non-tertiary tetroxides follows the same asymmetric two-step bond cleavage pathway to form a caged intermediate of overall singlet multiplicity comprising triplet oxygen and two alkoxyl radicals. The alpha hydrogen atoms of non-tertiary species facilitate this process by forming unexpected $\mathrm{CH}---\mathrm{O}$ hydrogen bonds to the evolving $\mathrm{O}_{2}$. For nontertiary peroxyls, subsequent alpha hydrogen atom transfer then yields the experimentally observed non-radical products, ketone, alcohol and $\mathrm{O}_{2}$, whereas for tertiary species, this reaction is precluded and cage escape of the (unpaired) alkoxyl radicals is a likely outcome with important consequences for autoxidation.
\end{abstract}

\section{Introduction}

The reaction of organic compounds, $\mathrm{RH}$, in the gas, liquid, and solid phase with molecular oxygen in air at temperatures from $\sim 300$ - $400 \mathrm{~K}$ (autoxidations,) can generally be described by the radical chain process in Scheme 1 . In this paper we apply $a b$ initio calculations to explore the mechanism of reaction (4) for alkylperoxyls. These are unusual reactions because the two radical centres are destroyed at rates far below those of diffusion-control, the rate common to the vast majority of radical + radical reactions. Moreover, and as indicated by our title, the sec-ROO - bimolecular self-reactions are generally at least a thousand times faster than corresponding reactions of tert-ROO $\bullet .{ }^{1}$ Termination rate constants, $2 k_{\mathrm{t}}$, can be measured during an $\mathrm{RH}$ autoxidation using a variety of techniques, the most important being the Rotating Sector method. ${ }^{1}$ Interestingly, a significant fraction of the bimolecular selfreactions of tert-alkylperoxyls, but not of sec- (or prim-) alkylperoxyls, do not terminate oxidation chains. This becomes obvious when rate coefficients for reaction (4), $2 k_{4}$, are determined directly. This can be done most readily by generating the ROO - using a brief flash of UV light from a suitable precursor, e.g. $\mathrm{RN}=\mathrm{NR}, \mathrm{ROOH}$, etc., with decay of the ROO • then being monitored by ESR spectroscopy. ${ }^{1}$ For $s$-ROO•, $2 k_{\mathrm{t}}=2 k_{4}$, e.g., ${ }^{1}$ at $303 \mathrm{~K}$ with $\mathrm{RH}=1,2,3,4-$ tetrahydronaphthalene (tetralin) $2 k_{\mathrm{t}}=7.6 \times 10^{6} \mathrm{M}^{-1} \mathrm{~s}^{-1}$ and $2 k_{4}=$ $7.2 \times 10^{6} \mathrm{M}^{-1} \mathrm{~s}^{-1}$. What this means is that in the autoxidation of tetralin most, if not all, $s-\mathrm{ROO} \bullet+s-\mathrm{ROO} \bullet$ encounters that lead to reaction also lead to chain termination. The situation for $t$ ROO - is quite different with $2 k_{\mathrm{t}}>2 k_{4}$, e.g., ${ }^{1}$ for $\mathrm{RH}=2$ phenylpropane (cumene) at $303 \mathrm{~K}, 2 k_{\mathrm{t}}=1.5 \times 10^{4} \mathrm{M}^{-1} \mathrm{~s}^{-1}$ and $2 k_{4}$ $=0.58 \times 10^{4} \mathrm{M}^{-1} \mathrm{~s}^{-1}$, which means that during the autoxidation of cumene most $t$-ROO $\bullet+t$-ROO• encounters that lead to reaction do not lead to chain termination.

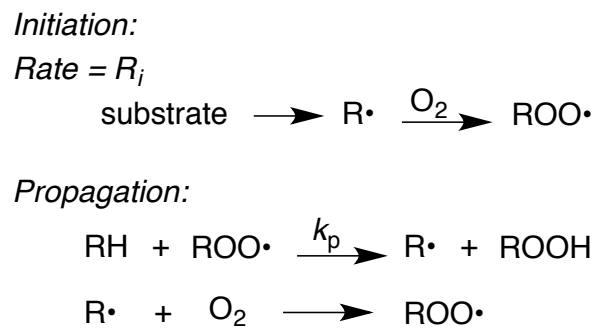

Termination: $\mathrm{ROO} \cdot+\mathrm{ROO} \cdot \stackrel{2 k_{\mathrm{t}}}{\longrightarrow} \begin{gathered}\text { non-radical } \\ \text { products }\end{gathered}$

Overall Oxidation Rate $=-d\left[\mathrm{O}_{2}\right] / d t=k_{p}\left(R_{i} / 2 k_{t}\right)^{0.5}$

Scheme 1. The Basic Autooxidation Scheme (BAS).

Our understanding of $t$-ROO $+t$-ROO $\bullet$ reactions is fairly comprehensive. These reactions yield the peroxide, $t$-ROOR- $t$, and $\mathrm{O}_{2}$ in what must be a head-to-head reaction since the autoxidation of cumene using a mixture of ${ }^{16} \mathrm{O}^{16} \mathrm{O}$ and ${ }^{18} \mathrm{O}^{18} \mathrm{O}$ resulted in the formation of ${ }^{16} \mathrm{O}^{18} \mathrm{O} .{ }^{2}$ Low temperature ESR studies, pioneered by Bartlett and Guaraldi, ${ }^{3}$ and soon extended by others, ${ }^{4}, 5$ revealed that at temperatures below $193 \mathrm{~K} t$ butylperoxyls decay at sufficiently slow rates that [ $\mathrm{Me}_{3} \mathrm{COO} \bullet$ ] can be increased and decreased reversibly by raising and lowering the temperature. Clearly, at these low temperatures the $\mathrm{Me}_{3} \mathrm{COO} \bullet$ radicals are in equilibrium with their tetroxide dimer, see Scheme 2 . The thermodynamic parameters for this equilibrium are: $1,4,5 \Delta \mathrm{S}_{5}=-30$ to $-34 \mathrm{cal} / \mathrm{deg} / \mathrm{mol}$ and $\Delta H^{\circ}{ }_{5}=-$ 8.0 to $-8.8 \mathrm{kcal} / \mathrm{mol}$. However, at temperatures above $158 \mathrm{~K}$ this tetroxide undergoes an irreversible decay with formation of a solvent-caged pair of $t$-butoxyl radicals, reaction (6). The geminate pair of $t$-butoxyls may combine (terminating the oxidation chain) or may diffuse out of the cage to continue the chain, reactions (7) and (8). The Arrhenius parameters for irreversible decomposition of di-t-butyl tetroxide have been reported ${ }^{5}$ to be: $\log \left(A_{6} / \mathrm{M}^{-1} \mathrm{~s}^{-1}\right)=16.6$ (consistent with the ratecontrolling scission of a single bond) and $E_{6}=17.5 \mathrm{kcal} / \mathrm{mol}$. Our knowledge about the much faster RRCHOO $+\mathrm{RRCHOO} \bullet$ reactions is also considerable but it does not extend to an acceptable reaction mechanism. 


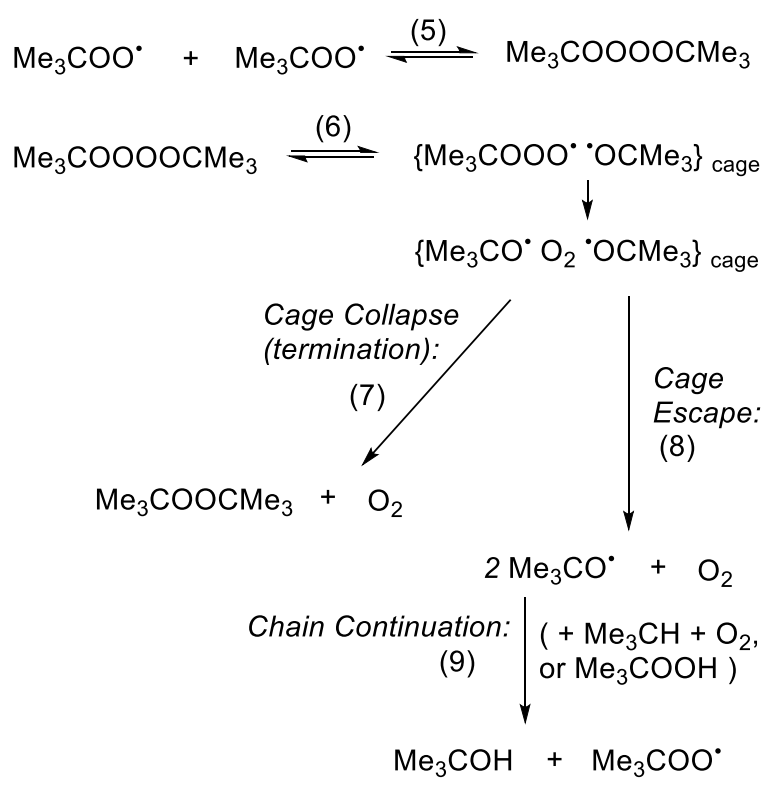

Scheme 2. Biomolecular self-reaction of $t$-butylperoxyl radicals

The main experimental facts are: ${ }^{1}$

1. All or nearly all of these reactions are chain terminating (meaning that if alkoxyl radicals are produced few escape mutual in-cage destruction).

2. The products are oxygen, plus the alcohol and ketone, the last two being formed in roughly equal amounts, reaction (10):

$$
\begin{gathered}
{\mathrm{R}\left(\mathrm{R}^{\prime}\right) \mathrm{CHOO}}^{*}+\mathrm{R}\left(\mathrm{R}^{\prime}\right) \mathrm{CHOO} \\
\mathrm{O}_{2}+\mathrm{R}\left(\mathrm{R}^{\prime}\right) \mathrm{CHOH}+\mathrm{R}\left(\mathrm{R}^{\prime}\right) \mathrm{C}=\mathrm{O}
\end{gathered}
$$

3. Values of $2 k_{10}$ for $\mathrm{R}\left(\mathrm{R}^{\prime}\right) \mathrm{CHOO}$ - having unactivated $\alpha-\mathrm{C}-\mathrm{H}$ bonds are up to an order of magnitude smaller than for $\mathrm{R}\left(\mathrm{R}^{\prime}\right) \mathrm{CHOO} \bullet$ that have an $\alpha-\mathrm{H}$ activated by a neighboring vinyl or phenyl group.

4. Replacement of the $\alpha-\mathrm{H}$ by an $\alpha-\mathrm{D}$ reduces $2 k_{10}$ by $25-30 \%$

5. The $\mathrm{O}_{2}$ is derived from two different $s-\mathrm{ROO} \bullet$ radicals (as is also the case for $t$-ROO•). ${ }^{6}$

6. At least some of the $\mathrm{O}_{2}$ is produced in singlet electronic excited states, ${ }^{1} \Delta$ and ${ }^{1} \sum{ }^{7}$

7. At least some of the ketone is produced in its triplet excited state, ${ }^{3} R, R^{\prime} C=O$, the decay of which to its singlet ground state causes this reaction to emit luminescence. ${ }^{8}$

8. At temperatures below $173 \mathrm{~K}, \mathrm{~s}$-ROO - radicals are, like $t$ ROO•, in equilibrium with their tetroxides, and within the limits of experimental error, the magnitudes of $\Delta S^{\circ}$ and $\Delta H^{\circ}$ are not influenced by the structure of R. For example, ${ }^{9}$ $\Delta S^{\circ}{ }_{11}$ and $\Delta H^{\circ}{ }_{11}$ for $\mathrm{Me}_{2} \mathrm{CDOOOOCDMe} 2$, are $-33 \pm 3$ $\mathrm{cal} / \mathrm{deg} / \mathrm{mol}$ and $-8.0 \pm 0.4 \mathrm{kcal} / \mathrm{mol}$, values that are essentially the same as the experimental $\Delta S^{\circ}$ and $\Delta H^{\circ}{ }_{5}$ values reported above for $\mathrm{Me}_{3} \mathrm{COOOOCMe}_{3}$ (and other $t$ ROOOOR- $t$ ). However, $s$-ROO• undergo irreversible decay at temperatures where the $t$-ROO $\bullet$ do not. This implies that $s$-ROOOOR-s tetroxides decompose irreversibly by a process having a significantly lower free energy barrier than that required for the irreversible decay of $t$-ROOOOR$t$.

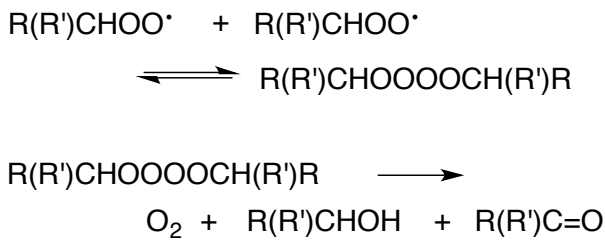

With only a few of the above facts available in 1957, Russell ${ }^{10}$ made the brilliant proposal that di-s-alkyl tetroxides decomposed via a cyclic transition state as shown in Scheme 3. This decomposition mechanism is not available to di-t-alkyl tetroxides and it provides a rationale to explain why chain terminations involving $t$-ROO• were so much slower than those involving $s-\mathrm{ROO} \bullet$. Moreover, this Russell mechanism appears to be consistent with all eight of the experimental facts listed above. ${ }^{11}$

The Russell mechanism was, therefore, generally accepted ${ }^{12}$ despite a few anomalies. Among these anomalies was the observation that certain $s$-ROO $+s$-ROO $\bullet$ reactions yielded some $s$-RO• radicals and $s$-ROOR-s. ${ }^{13}$ Another anomaly was Howard and Bennett's ${ }^{14}$ ESR kinetic studies of the self-reactions of cyclopentylperoxyl, cyclopentenylperoxyl, and s-butylperoxyl radicals from 257 to $133 \mathrm{~K}$, which yielded, respectively, the Arrhenius parameters; $\log \left(A / \mathrm{M}^{-1} \mathrm{~s}^{-1}\right)=10.0,7.8$, and 9.0 and $E_{\mathrm{a}}$ $=3.1,1.0$, and $2.7 \mathrm{kcal} / \mathrm{mol}$. These activation enthalpies were much lower than that found for $t$-butylperoxyl $(7.7,14$ consistent with the much faster $s-\mathrm{ROO} \bullet+s-\mathrm{ROO} \cdot$ reactions), but these $\log A$ values bracketed the 9.2 found for $t$-butylperoxyl. The similar entropic changes for the $s$-ROO and the $t$-ROO• bimolecular self-reactions are, as Howard and Bennett ${ }^{14}$ noted, inconsistent with "the currently accepted Russell mechanism" (which, with its cyclic transition state, must have a lower $\log A$ than the 7.8-10 actually found). In later work, the Howard group ${ }^{9}$ measured the Arrhenius parameters for decay of dicyclopentyl tetroxide: $\log \left(A_{12} / \mathrm{s}^{-1}\right)=12$ and $E_{12}=10 \mathrm{kcal} / \mathrm{mol}$. Within experimental error, $A_{12}$ is the same as $A_{6}$. Both implied rate-controlling single bond scissions but provided no explanation for the fact that the scission $s$-RO-OOOR-s has a lower enthalpy barrier than the $t$-RO-OOOR- $t$ scission.

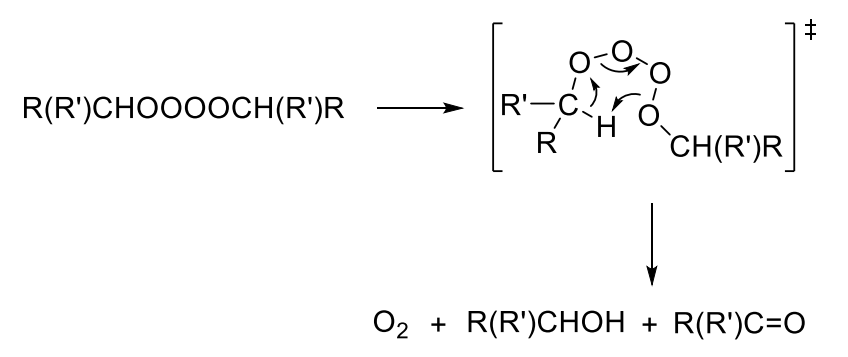

Scheme 3. Russell ${ }^{10}$ mechanism for chain termination by $s$-ROO• radicals.

Serious reservations about the Russell mechanism also arise from the studies of Mendenhall and Quinga ${ }^{15,16}$ on the behaviour of $s$-alkoxyl radicals generated as geminate (singlet) 
pairs by thermal decomposition of di-s-alkyl hyponitrites, see Scheme 4. Hyponitrites have the E-configuration, which makes decomposition via a cyclic Russell-type mechanism impossible. Nevertheless, this reaction (when $\mathrm{R}, \mathrm{R}^{\prime} \mathrm{CH}=\mathrm{PhCHMe}, \mathrm{Me}_{2} \mathrm{CH}, \mathrm{c}^{-}$ $\mathrm{C}_{6} \mathrm{H}_{11}, \mathrm{PhCH}_{2}$, but not $\left.\mathrm{Me}_{3} \mathrm{C}\right)^{15}$ produces chemiluminescence with a high efficiency from decay of the electronically excited ketone triplet, (e.g., ${ }^{3} \mathrm{~T} /{ }^{1} \mathrm{~S}>1500$ from 1-phenylethyl hyponitrite at $322 \mathrm{~K}$ ). Such chemiluminescence has long been known in autoxidations and has been attributed to the $s-\mathrm{ROO} \bullet+s-\mathrm{ROO} \bullet$ chain termination reactions. ${ }^{17,18}$ Mendenhall and Quinga also demonstrated $^{16}$ that the thermal decomposition (304-348 K) of three di-s-alkyl hyponitrites in hydrocarbon solvents gave the ketone in $6-8 \%$ lower yield when the two $\alpha-\mathrm{H}$ atoms were replaced by two deuterium atoms. This was ascribed to a competition between in-cage dismutation of the two alkoxyls and cage escape (favored for the $\alpha$-deutero-alkoxyls). It was very sensibly suggested that the slower termination of 2 $\mathrm{R}, \mathrm{R}^{\prime} \mathrm{CDOO} \bullet$ than $2 \mathrm{R}, \mathrm{R}^{\prime} \mathrm{CHOO} \bullet$ might well arise from the same competition. ${ }^{16}$ Finally, it is worth noting that theoretical studies in the literature ${ }^{19-23}$ and the present work (Appendix S1 of the ESI) indicate that the barrier to a Russell concerted process is far too large for that mechanism to make any meaningful contribution to this very fast reaction.

To sum up, the 1957 Russell mechanism for the 2 s-ROO• reaction has been unacceptable for well over 30 years but no reasonable alternative has yet emerged. In earlier work ${ }^{24,}{ }^{25}$ we have had some success in distinguishing between possible reaction mechanisms in extremely complex systems by utilizing ab initio modelling to explore the full energy surface facing the reactants. In this paper, we take the same approach to our "problem" reaction. ${ }^{26}$

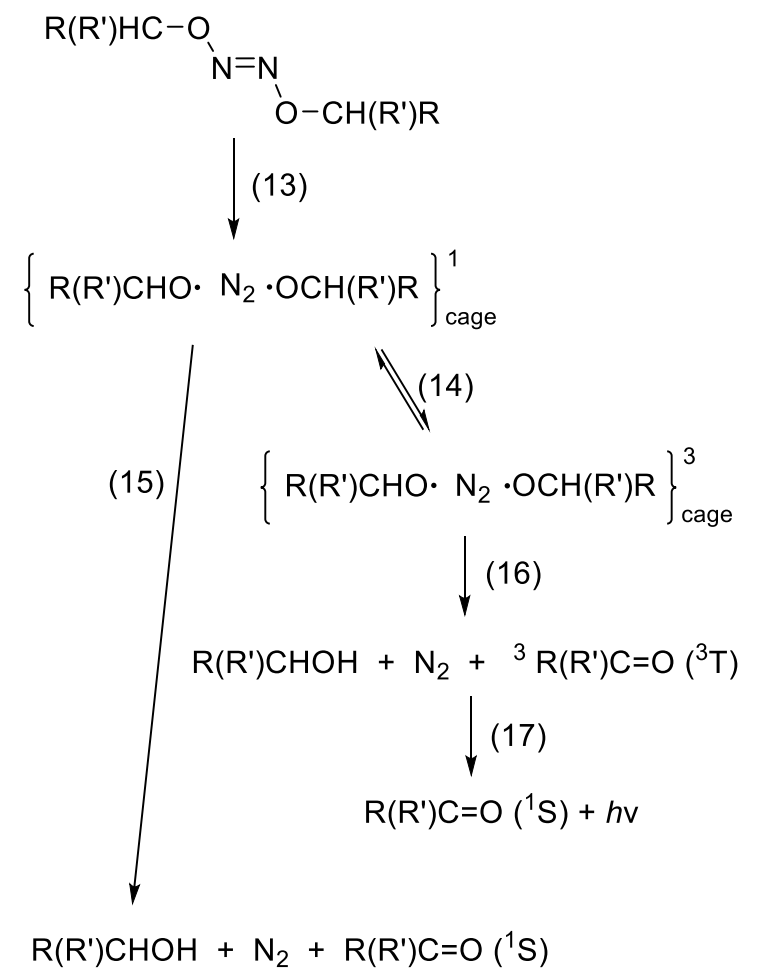

Scheme 4. Thermal decomposition of di-s-alkyl hyponitrites.

\section{Computational Methods}

In selecting an accurate but cost-effective procedure for the current work, the previous work of Bach et al 27, 28 is relevant. They employed broken symmetry unrestricted DFT to explore the energetic landscape of peroxynitrous acid's dissociation to caged radical intermediates and their reactivity towards oxidative transformation of organic molecules. Importantly, they were able to computationally identify the metastable singlet biradicaloid caged radical species minimum and also successfully located the O-O bond homolysis transition state (TS) using unrestricted DFT, for which energies were comparable to the more accurate and expensive multireference CASSCF method. In the present work we have used the broken symmetry unrestricted DFT (UDFT) protocol by first generating an initial guess of the biradicaloid minimum or TS geometry with mixed HOMO and LUMO $\left(<S^{2}>\approx 1\right)$ using the guess=mix keyword in Gaussian 0929, the software package used for calculations in this work. Geometries were optimized with Truhlar's ${ }^{30}$ dual range meta-hybrid functional M11 using the $6-31+G(d, p)$ Pople basis set. ${ }^{31-33}$ Electronic energies were further refined with highly correlated $\operatorname{CCSD}(T)$ method $^{34-36}$ and Dunning's double $\zeta$ cc-pVDZ basis sets ${ }^{35}$ (see the ESI for further details). Gibbs' free energy values reported in the manuscript have been calculated with $\operatorname{CCSD}(T)$ energies and $M 11 / 6$ $31+G(d, p)$ thermal and entropic corrections (298K).

\section{Results}

To determine how non-tertiary radicals behave we first considered the self-reaction of EtOO• and decomposition of the resulting tetroxide, and calculated the barrier heights and reaction energies for all the literature proposed pathways for this process. Full details of the results are given in Appendix S1 of the $\mathrm{SI}$, from which it is clear that the majority of proposed pathways, including the Russell mechanism, involve barriers far too high to be kinetically relevant. Instead, the preferred pathway for the EtOO - radicals is that shown in Scheme 5, and involves the same asymmetric cleavage process $B$ that is known to occur for tertiary radicals in which consecutive single bond cleavage leads to formation of overall singlet cage containing ${ }^{3} \mathrm{O}_{2}$ (spin up) and two same-spin $\mathrm{RO} \bullet$ (spin down). ${ }^{6}$ For EtOO• (and other primary and secondary alkyl radicals), the two RO• can undergo alpha hydrogen transfer $\mathrm{H}$ to yield the experimentally observed products, oxygen, alcohol and ketone. The direct reaction yields triplet ketone and triplet oxygen, but singlet oxygen is also produced ${ }^{37}$ via the very fast reaction I between the triplet ketone and triplet oxygen. For tertiary alkyl radicals, this hydrogen transfer reaction is, of course, not available. Moreover, the same-spin RO • radicals cannot yield ROOR without first undergoing a spin-flip $E$. This makes cage escape $D$ a more likely possibility for the t-RO $\bullet$ pair, and is consistent with the experimental observation that a significant 
fraction of reacting t- ROO• pairs do not terminate oxidation chains (vide supra).

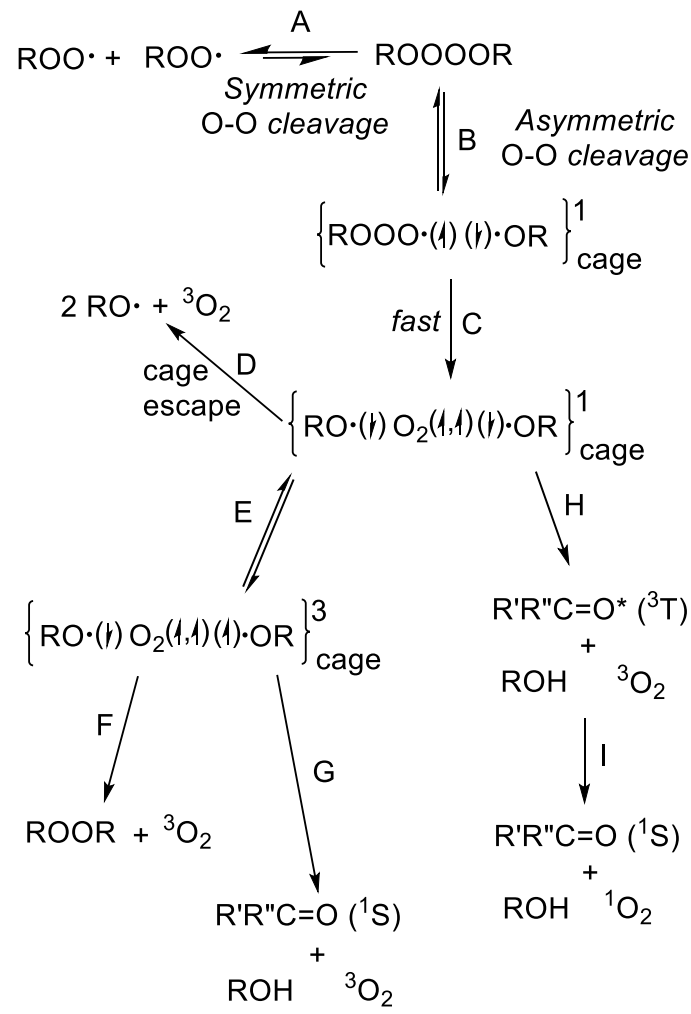

Scheme 5. Lowest Gibbs free energy pathways for the bimolecular self-reactions of alkylperoxyls. Note that reactions $\mathrm{G}, \mathrm{H}$ and I are not available to tert-alkylperoxyls.

Table 1. Reaction Gibbs free energies and free energy barriers for the elementary processes listed in Scheme 5 . $^{\text {a }}$

\begin{tabular}{|c|c|c|c|c|c|c|}
\hline \multirow[b]{2}{*}{$\begin{array}{l}\text { Path } \\
\text { way }\end{array}$} & \multicolumn{2}{|c|}{$\mathrm{R}=n-\mathrm{Bu}$} & \multicolumn{2}{|c|}{$\mathrm{R}=s-\mathrm{Bu}$} & \multicolumn{2}{|c|}{$\mathrm{R}=t-\mathrm{Bu}$} \\
\hline & $\begin{array}{l}\Delta G^{\ddagger} \\
\text { (kcal/ } \\
\text { mol) }\end{array}$ & $\begin{array}{l}\Delta G_{\mathrm{rxn}} \\
\text { (kcal/ } \\
\text { mol) }\end{array}$ & $\begin{array}{l}\Delta G^{\ddagger} \\
\text { (kcal/ } \\
\text { mol) }\end{array}$ & $\begin{array}{l}\Delta G_{\mathrm{rxn}} \\
\text { (kcal/ } \\
\mathrm{mol})\end{array}$ & $\begin{array}{l}\Delta G^{\ddagger} \\
\text { (kcal/ } \\
\text { mol) }\end{array}$ & $\begin{array}{l}\Delta G_{\mathrm{rxn}} \\
\text { (kcal/ } \\
\mathrm{mol}) \\
\end{array}$ \\
\hline$A$ & +13.5 & +5.2 & +12.5 & +5.2 & +14.8 & +7.8 \\
\hline B & +19.8 & +16.4 & +21.3 & +17.5 & +24.6 & +22.4 \\
\hline$C$ & +11.0 & +1.9 & +7.7 & +2.8 & +18.4 & +7.1 \\
\hline $\mathrm{D}$ & $b$ & -14.8 & $b$ & -11.5 & b & -9.7 \\
\hline$E$ & $b$ & +0.3 & $b$ & +1.6 & $b$ & +6.6 \\
\hline $\mathrm{F}$ & $b$ & -33.5 & $b$ & -35.4 & $b$ & -33.3 \\
\hline G & b & -95.5 & $b$ & -95.7 & $c$ & c \\
\hline $\mathrm{H}$ & +7.6 & -22.1 & +5.0 & -21.6 & $c$ & $c$ \\
\hline I & $b$ & -74.7 & $b$ & -76.9 & $c$ & $c$ \\
\hline
\end{tabular}

a Free energy barriers $\left(\Delta G^{\ddagger}\right)$ and reactions $\left(\Delta G_{\mathrm{rxn}}\right)$ are gas-phase $\operatorname{CCSD}(T) / \mathrm{cc}-\mathrm{pVDZ}$ electronic energies inclusive of thermal, zero-point energy and vibrational corrections from DFT M11/6-31+G(d,p) optimized equilibrium or first order saddle-point structures. All barriers and reaction energies are calculated with respect to the energies of the two isolated ROO - radicals. ${ }^{b}$ Barrierless. ${ }^{c}$ These reactions are not available to tertalkylperoxyls.

Having established the reaction mechanism, we then studied the effect of the substitution of $R$ on the barrier heights and reactions energies for the series $n$-BuOO•, $s$-BuOO• and $t$ -
BuOO• (Table 1). Crucially, the calculated activation barrier for the rate determining asymmetric cleavage $B$ with reference to the respective peroxyls is significantly higher for tertiary alkyl versus secondary (or primary) alkyl radicals $\left(\Delta \Delta G^{\ddagger}=\sim 3 \mathrm{kcal} \mathrm{mol}^{-}\right.$ 1).

Although this result was consistent with the experimental facts, it could only be understood after a careful examination of the relevant transition states, see Figure 1. For primary and secondary species, the $\mathrm{C}_{\alpha}-\mathrm{H}$ hydrogen atoms appear to form hydrogen bonds with both of the $\mathrm{O}$-atoms of the evolving $\mathrm{O}_{2}$. For these species $\mathrm{C}_{\alpha}-\mathrm{H} \cdots \mathrm{O}$ contacts are considerably less than the sum of the van der Waals radii for $\mathrm{H}$ and $\mathrm{O}$ (viz., 2.7 ${ }^{38}$ ), with one contact (2.29尺̊) slightly shorter than the other (2.36$7 \AA ̊)$. For the tertiary system, the lack of an alpha hydrogen means that the closest $\mathrm{C}-\mathrm{H} \cdots \mathrm{O}$ contacts on each side involve beta hydrogens and are close to the van der Waals distance (2.55 to $2.60 \AA ̊$ ).

To help confirm the presence of hydrogen bonding interactions, we performed the reduced density gradient based non-covalent interaction $(\mathrm{NCl})$ analysis ${ }^{39}, 40$ and calculated the Density Overlap Regions Indicator (DORI) ${ }^{41}$ compactness indices (see Figure 1 and Appendix S2 of the ESI). In this method, the orbitalfree density-dependent scalar field is employed to construct the DORI isosurfaces, which enclose regions of electron overlap. Integration over the volume of such domains provides an indirect measure of the non-covalent interaction strength. Interestingly, these results indicate that both $\mathrm{C}_{\alpha}-\mathrm{H}^{\cdots} \mathrm{O}$ and $\mathrm{C}_{\beta^{-}}$ $\mathrm{H} \cdots \mathrm{O}$ interactions are involved in stabilizing the transition states though, as expected, the shorter $\mathrm{C}_{\alpha}-\mathrm{H} \cdots \mathrm{O}$ interactions are stronger, hence explaining the lower reaction barriers for the species with alpha hydrogens (Figure 1).

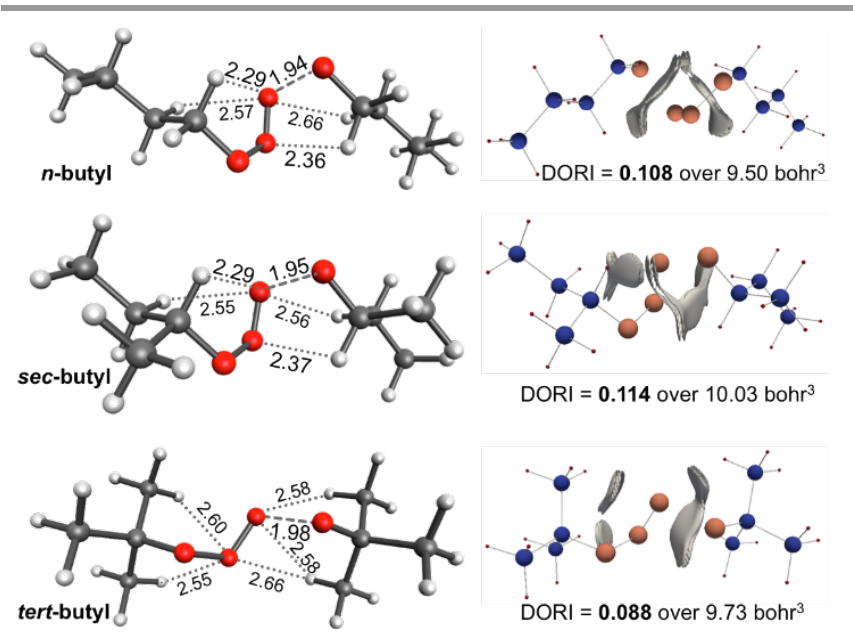

Figure 1. Optimized transition state structures for asymmetric breaking of the $\mathrm{O}-\mathrm{O}$ bond in the three di-butyl-tetroxide isomers (left). $\mathrm{H}$-bonding interactions between each alpha hydrogen on RR'CHO moiety and the evolving $\mathrm{O}_{2}$ in the tetroxide are emphasized by the $\mathrm{C}_{\alpha}-\mathrm{H} \cdots \mathrm{O}$ distances of $2.29 \AA$ and $2.36-7 \AA$, which are notably less than the sum of the $\mathrm{O}$ and $\mathrm{H}$ van der Waals radii, viz., $2.7 \AA .^{38}$ Beta hydrogen $\mathrm{C}_{\beta}-\mathrm{H} \cdots \mathrm{O}$ contacts are within 2.55 to $2.60 \AA$. Cumulative Density Overlap Regions Indicator (DORI) compactness indices quantify the strength of non-covalent interactions, corresponding to the electron density overlap regions, enclosed by DORI isosurfaces at the 0.95 isovalue (right). 
To assess the energetic importance of hydrogen bond formation, we calculated the energy for formation of hydrogenbonded complexes between $s$ - and $t$-dibutyl tetroxides and $\mathrm{CH}_{3} \mathrm{OCH}_{3}$ (see ESI). Our calculations indicate that the $\alpha-\mathrm{CH}$ in disec-alkyl tetroxides are sufficiently strong hydrogen bond donors that they form bifurcated hydrogen bonds with an added molecule of dimethyl ether. The intramolecular 5membered ring hydrogen bond is not broken but a new intermolecular hydrogen bond is formed with the O-atom of this ether. Whether stronger hydrogen bond acceptors would break the intramolecular hydrogen bond was not explored.

\section{Discussion}

Hydrogen bond formation by a $\mathrm{C}-\mathrm{H}$ moiety was difficult to accept until we recalled that the $\mathrm{O} \bullet$ moiety is an extremely strong electron-withdrawing substituent, ${ }^{42}$ and that the alpha hydrogen atoms in alkoxyl radicals are highly acidic, e.g., $\mathrm{p} K_{\mathrm{a}}$ 's for the $\mathrm{C}_{\alpha}-\mathrm{H}$ in $\mathrm{MeCH}_{2} \mathrm{O}$ - and $\mathrm{PhCH}_{2} \mathrm{O}$ - have been estimated roughly as 1 and -3 , respectively. ${ }^{43}$ Such high acidities imply that these $\mathrm{C}_{\alpha}-\mathrm{H}$ hydrogen atoms should be excellent hydrogen bond donors. Furthermore, even sterically encumbered di-t-butyl peroxide is a moderately good hydrogen bond acceptor (HBA), $\mathrm{BH}_{2}=0.33,{ }^{44}$ comparable in HBA activity to nitrobenzene or aniline. Indeed, hydrogen bond formation between the $\mathrm{CH}$ hydrogen atoms in $\mathrm{PhCH}_{2} \mathrm{O}$ - and a variety of hydrogen bond acceptor (HBA) substrates has been unequivocally identified by Salamone, Bietti, and DiLabio. ${ }^{45-49}$ These workers found that $\mathrm{PhCH}_{2} \mathrm{O} \bullet$ was considerably more reactive than $\mathrm{PhCMe}_{2} \mathrm{O} \bullet$ towards many HBA substrates, whereas towards non-HBA substrates these two radicals had essentially identical reactivities. For example, ${ }^{45}$ the rate constant ratios, $k\left(\mathrm{PhCH}_{2} \mathrm{O} \bullet\right) / k\left(\mathrm{PhCMe}_{2} \mathrm{O} \bullet\right)$, for the following substrates were: 21.5 triethylamine; $37 \quad d_{15}$-triethylaine; $1094 \quad$ 1,4diazabicyclo[2.2.2] octane (DABCO); but only 1.9 for 1,4cyclohexadiene. The enthalpy of the $\mathrm{HB}$ in the pre-reaction complex between $\mathrm{PhCH}_{2} \mathrm{O}$ - and an $\mathrm{N}$-atom in DABCO was calculated to be $-4.0 \mathrm{kcal} / \mathrm{mol} .45$ Rate constant ratios, $k\left(\mathrm{PhCH}_{2} \mathrm{O} \bullet\right) / k\left(\mathrm{PhCMe}_{2} \mathrm{O} \bullet\right)$, were also found to be $>>1$ for many other HBAs. ${ }^{46-49}$ These studies support the idea that HB formation would occur between the $\mathrm{C}_{\alpha}-\mathrm{H}$ of an incipient salkoxyl and an O-atom in the decomposing tetroxide. Furthermore, such a $\mathrm{C}_{\alpha}-\mathrm{H} \cdots \mathrm{O} \mathrm{HB}$ would be expected to greatly weaken a neighboring $\mathrm{O}-\mathrm{O}$ bond in the tetroxide since intramolecular $\mathrm{HB}$ formation is known to decrease the BDE of the "free" OH (i.e., the HBA OH group) in both catechols and 1,8-dihydroxynaphthalenes 50 (via 5- and 6-membered rings, respectively). In these compounds, the intramolecular $\mathrm{HBs}$ produce dramatic $(5-9 \mathrm{kcal} / \mathrm{mol}){ }^{50}$ reductions in the O-H BDE of the "free" $\mathrm{OH}$ group. An intramolecular $\mathrm{CH} \cdots \mathrm{O}$ HB-induced decrease in the $s$-ROOO-OR-s BDE of ca $3-5 \mathrm{kcal} / \mathrm{mol}$ (compared with the $t$-ROOO-OR- $t$ ) would be quite sufficient to make the free energy barrier for irreversible decay of the former tetroxides only marginally higher than their barrier for reversible decay to $2 \mathrm{~s}$-ROO•, as observed experimentally.

Finally, we note that the mechanism of the bimolecular selfreactions of peroxyl radicals containing $\alpha-\mathrm{H}$-atoms is almost certainly the same in the gas phase as in solution, except that the absence of a solvent-cage effect in the gas phase can influence the post-transition state partitioning into products. Thus, the rate constants measured in solution by ESR at $229 \mathrm{~K}$ (and below) for the bimolecular self-reaction of $\left(\mathrm{CH}_{3}\right)_{2} \mathrm{CHOO}$ are in excellent agreement with rate constants calculated using the Arrhenius parameters reported ${ }^{51}$ for this reaction that are based on a higher temperature ( $300-373 \mathrm{~K}$ ) gas-phase study. ${ }^{9}$ In addition, although detailed kinetic and product studies of the $2 \mathrm{MeOO} \bullet$ and $2 \mathrm{EtOO} \bullet$ reactions in the gas phase have provided none of the insight into the fine details of reaction mechanisms that we have addressed, they do reveal that the so-called branching ratio: ["free" alkoxyl] / [molecular products] $=k_{18} /\left(k_{19}\right.$ $+k_{20}$ ) (see Scheme 6), is considerably higher in the gas phase than in solution ${ }^{52-56}$ (where few "free" alkoxyl radicals escape the cage, vide supra). Moreover, this ratio has been reported to increase as the temperature is increased ${ }^{55}$ (a result congruent with our proposed mechanism). That is, in the gas phase, just as we have concluded for the liquid phase, all product-forming reactions involving two $\mathrm{RR}^{\prime} \mathrm{CHOO}$ - radicals lead to the reversible formation of a tetroxide, which decomposes irreversibly to yield a geminate pair of $\mathrm{RR}^{\prime} \mathrm{CHO} \cdot$ radicals, there being no intramolecular rearrangement of the tetroxide, i.e., no Russell-type reaction.

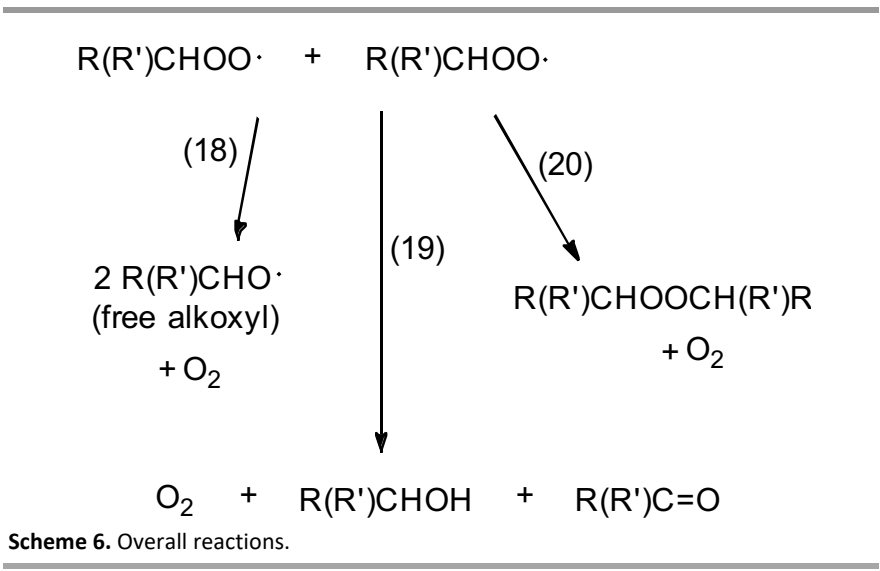

\section{Acknowledgements}

M.L.C gratefully acknowledges generous allocations of supercomputing time on the National Facility of the Australian National Computational Infrastructure and financial support from the Australian Research Council Centre of Excellence for Electromaterials Science. The Laboratory for Computational Molecular Design at EPFL is acknowledged by G.G. for providing computational resources.

\section{Notes and references}

¥ Appendix sections on detailed discussions of the computational modelling, cartesian coordinates of optimized geometries of electronic structures, $\operatorname{CCSD}(\mathrm{T})$ energies and associated total entropies or energy corrections are available in the ESI.

1. J. A. Howard, Peroxyl Radicals. Z. B. Alfassi Ed. Wiley: New York, 1997 pp 283-334. This excellent review contains a host of rate and equilibrium 
constants for ROO reactions, all properly cited. Therefore we will reference only publications that are particularly germane to our subject.

2. P. D. Bartlett and T. G. Traylor, J. Am. Chem. Soc., 1963, 85, 2407-2410.

3. P. D. Bartlett and G. Guaraldi, J. Am. Chem. Soc., 1967, 89, 4799-4801.

4. J. E. Bennett, D. M. Brown and B. Mile, Chem. Commun., 1969, 504-505.

5. K. Adamic, J. A. Howard and K. U. Ingold, Chem. Commun., 1969, 505-506

6. J. E. Bennett and J. A. Howard, J. Am. Chem. Soc., 1973, 95, 4008-4010.

7. , The yield of singlet oxygen is ca. 0.1 for chain termination in the autoxidation of variety of hydrcarbons yielding sec- (and prim-) peroxyls, see G. Niu and G. D. Mendenhall, J. Am. Chem. Soc. 1990, 112, 1656-1657.

8. , The yield of triplet carbonyls is very much lower than the yields of singlet oxygen, see: G. D. Mendenhall, X. C. Sheng, and T. Wilson, J. Am. Chem. Soc. 1991, 113, 8976-8977.

9. E. Furimsky, J. A. Howard and J. Selwyn, Can. J. Chem., 1979, 58, 677-680.

10. G. A. Russell, J. Am. Chem. Soc., 1957, 79, 3871-3877.

11. According to the Wigner spin conservation rule, a concerted decomposition of the (singlet) tetroxide must either produce oxygen in an excited singlet state, ${ }^{1} \mathrm{O}_{2}$, and the ketone in its ground (singlet) state, or produce ground state (triplet) oxygen, ${ }^{3} \mathrm{O}_{2}$, together with the ketone in its excited triplet state, $R, R^{\prime \prime} C=O^{*}\left({ }^{3} T\right)$. The latter process would also yield ${ }^{1} \mathrm{O}_{2}$ via the fast triplet-triplet reaction: ${ }^{3} \mathrm{O}_{2}+\mathrm{R}, \mathrm{R}^{\prime} \mathrm{C}=\mathrm{O}^{*}\left({ }^{3} \mathrm{~T}\right) \rightarrow{ }^{1} \mathrm{O}_{2}+$ $\mathrm{R}, \mathrm{R}^{\prime} \mathrm{C}=\mathrm{O}\left({ }^{1} \mathrm{~S}\right)$

12. Formation of a Criegee zwitterion intermediate: $\mathrm{R}, \mathrm{R}^{\prime} \mathrm{CHOO} \bullet+\mathrm{R}, \mathrm{R}^{\prime} \mathrm{CHOO} \bullet$ $\rightarrow R, R^{\prime} \mathrm{CHOOH}+\mathrm{R}, \mathrm{R}^{\prime} \mathrm{C}=+\mathrm{OO}$ - has been suggested, see: P. S. Nangia and $\mathrm{S}$. W. Benson, Int. J. Chem. Kinet. 1980, 12, 29-42, but this was quickly discounted by experiment, see: A. Baignee, J. H. B. Chenier and J. A. Howard, Can. J. Chem. 1983, 81, 870-880. Our present calculations (see Supporting Information) indicate that this reaction has far too large a barrier to play any significant role in chain termination.

13. D. Lindsay, J. A. Howard, E. C. Horswill, L. Iton, K. U. Ingold, T. Cobbley and A. LL, Can. J. Chem., 1973, 51, 870-880.

14. J. A. Howard and J. E. Bennett, Can. J. Chem., 1972, 50, 2374-2377.

15. E. M. Y. Quinga and G. D. Mendenhall, J. Am. Chem. Soc., 1983, 105, 6520-6521.

16. E. M. Y. Quinga and G. D. Mendenhall, Int. J. Chem. Kinet., 1985, 17, 1187-1190.

17. R. F. Vassil'ev, Progr. Reaction Kinetics, 1957, 4, 305-350.

18. R. E. Kellogg, J. Am. Chem. Soc., 1969, 91, 5433-5436.

19. G. Ghigo, A. Maranzana and G. Tonachini, J. Chem. Phys., 2003, 118 10575-10583.

20. A. F. Jalbout, Z. Zhou, X. H. Li, Y. Shi and A. Kosmas, Chem. Phys. Lett., 2006, 420, 215-220.

21. G. da Silva and J. W. Bozzelli, J. Phys. Chem. A, 2007, 111, 12026-12036.

22. Y.-N. Liang, J. Li, Q.-D. Wang, F. Wang and X.-Y. Li, J. Phys. Chem. A, 2011 115, 13534-13541.

23. P. Zhang, W. Wang, T. Zhang, L. Chen, Y. Du, C. Li and J. Lü, J. Phys. Chem. A, 2012, 116, 4610-4620.

24. G. Gryn'ova, K. U. Ingold and M. L. Coote, J. Am. Chem. Soc., 2012, 134, 12979-12988.

25. G. Gryn'ova, C. Y. Lin and M. L. Coote, Polymer Chem., 2013, 4, 37443754 .

26. None of the earlier theoretical studies of the $2 s-\mathrm{ROO} \bullet, 2 p$-ROO•, and 2 $\mathrm{MeOO} \bullet$ reactions and of their corresponding tetroxides ${ }^{19-23}$ have provided any explanation for the question raised in our title, nor have they identified (as we do) $\mathrm{C}-\mathrm{H}--\mathrm{O}$ hydrogen bonding and the consequent weakening of neighboring $\mathrm{O}-\mathrm{O}$ bonds as being responsible for the much lower stability of these tetroxides relative to $t$-ROOOOR- $t$. .

27. R. D. Bach, O. Dmitrenko and C. M. Estévez, J. Am. Chem. Soc., 2005, 127, 3140-3155.

28. R. D. Bach, O. Dmitrenko and C. M. Estévez, J. Am. Chem. Soc., 2003, 52, 16204-16205.

29. Gaussian 09, Revision D.01, M. J. Frisch, G. W. Trucks, H. B. Schlegel, G. E. Scuseria, M. A. Robb, J. R. Cheeseman, G. Scalmani, V. Barone, B. Mennucci, G. A. Petersson, H. Nakatsuji, M. Caricato, X. Li, H. P. Hratchian, A. F. Izmaylov, J. Bloino, G. Zheng, J. L. Sonnenberg, M. Hada, M. Ehara, K. Toyota, R. Fukuda, J. Hasegawa, M. Ishida, T. Nakajima, Y. Honda, O. Kitao, H. Nakai, T. Vreven, J. Montgomery, J. A. , J. E. Peralta, F. Ogliaro, M. Bearpark, J. J. Heyd, E. Brothers, K. N. Kudin, V. N Staroverov, R. Kobayashi, J. Normand, K. Raghavachari, A. Rendell, J. C. Burant, S. S. Iyengar, J. Tomasi, M. Cossi, N. Rega, J. M. Millam, M. Klene,
J. E. Knox, J. B. Cross, V. Bakken, C. Adamo, J. Jaramillo, R. Gomperts, R. E. Stratmann, O. Yazyev, A. J. Austin, R. Cammi, C. Pomelli, J. W. Ochterski, R. L. Martin, K. Morokuma, V. G. Zakrzewski, G. A. Voth, P. Salvador, J. J. Dannenberg, S. Dapprich, A. D. Daniels, Ö. Farkas, J. B. Foresman, J. V. Ortiz, J. Cioslowski and D. J. Fox, Gaussian Inc., Wallingford CT, 2013.

30. R. Peverati and D. G. Truhlar, J. Phys. Chem. Lett., 2011, 2, 2810-2817.

31. R. Ditchfield, W. J. Hehre and J. A. Pople, J. Chem. Phys., 1971, 54, 724728.

32. W. J. Hehre, R. Ditchfield and J. A. Pople, J. Chem. Phys., 1972, 56, 2257 2261.

33. P. C. Hariharan and J. A. Pople, Theor. Chem. Acc., 1973, 28, 213-222.

34. R. J. Bartlett and M. Musiał, Rev. Mod. Phys., 2007, 79, 291-352.

35. T. H. Dunning Jr., J. Chem. Phys., 1989, 90, 1007-1023.

36. J. A. Pople, M. Head-Gordon and K. Raghavachari, J. Chem. Phys., 1987, 87, 5968-5975.

37. G. Niu and G. D. Mendenhall, J. Am. Chem. Soc., 1990, 112, 1656-1657.

38. A. Bondi, J. Phys. Chem., 1964, 64, 441-451.

39. E. R. Johnson, S. Keinan, P. Mori-Sanchez, J. Contreras-Garcia, A. J. Cohen and W. Yang, J. Am. Chem. Soc. , 2010, 132, 6498-6506.

40. J. Contreras-Garcia, E. R. Johnson, S. Keinan, R. Chaudret, J.-P. Piquemal, D. N. Beratan and W. Yang, J. Chem. Theory Comput. , 2011, , 7, 625-632.

41. P. de Silva and C. Corminboeuf, J. Chem. Theory Comput., 2014, 10, 37453756.

42. Probably even stronger than the $\mathrm{NO}_{2}$ group, see: D. A. Pratt, G. A. DiLabio, L. Valgimigli, G. F. Pedulli and K. U. Ingold, J. Am. Chem. Soc. 2002, 124, 11085-11092.

43. G. Merenyi cited in: K. G. Konya, T. Paul, S. Lin and J. Lusztyk, J. Am. Chem. Soc. 2000, 122, 7518-7527.

44. P. Mulder, H.-G. Korth, D. A. Pratt, G. A. DiLabio, L. Valgimigli, G. F. Pedulli and K. U. Ingold, J. Phys. Chem. A 2005, 109, 2647-2655; $\beta_{2}{ }_{2}$ values provide a thermodynamic scale of relative HBA activities of organic molecules for formation of 1:1 HB-complexes with HBDs, range 0.00 (alkanes) to 1.00 (HMPA, the strongest organic base). See: M. H. Abraham, P. L. Grellier, D. V. Prior, P. P. Duce, J. J. Morris and P. J. Taylor, J. Chem. Soc., Perkin Trans. 1990, 521-529.

45. M. Salamone, G. Anastasi, M. Bietti and G. A. DiLabio, Org. Lett., 2011, 13, 260-263.

46. M. Salamone, G. A. DiLabio and M. Bietti, J. Org. Chem., 2011, 76, 62646270.

47. M. Salamone, G. A. DiLabio and M. Bietti, J. Am. Chem. Soc., 2011, 133 16625-16634.

48. M. Salamone, G. A. DiLabio and M. Bietti, J. Org. Chem., 2012, 77, 1047910487.

49. M. Salamone, M. Milan, G. A. DiLabio and M. Bietti, J. Org. Chem., 2013, 78, 5909-5917.

50. M. C. Foti, L. R. C. Barclay and K. U. Ingold, J. Am. Chem. Soc., 2002, 124, 12881-12888.

51. L. J. Kirsch, D. E. Parkes, D. J. Waddington and A. Woolley, J. Chem. Soc., Faraday Trans. 1, 1978, 74, 2293-2300.

52. C. S. Kan, J. G. Calvert and J. H. Shaw, J. Phys. Chem., 1980, 84, 3411-3417.

53. H. Niki, P. D. Maker, C. M. Savage and L. P. Breitenbach, J. Phys. Chem., $1981,85,877-881$.

54. H. Niki, P. D. Maker, C. M. Savage and L. P. Breitenbach, J. Phys. Chem. 1982, 86, 3825-3829.

55. P. D. Lightfoot, R. Lesclaux and B. Veyret, J. Phys. Chem., 1990, 94, 700 707

56. A. C. Noell, L. S. Alconcel, D. J. Robichaud, M. Okumura and S. P. Sander, J. Phys. Chem., 2010, 114, 6983-6995. 